\title{
Subglottic Cancer pT4b TNM Finding v7
}

National Cancer Institute

\section{Source}

National Cancer Institute. Subglottic Cancer pT 4b TNM Finding v7. NCI Thesaurus. Code C89082.

Subg lottic cancer with very advanced local disease. Tumor invades prevertebral space, encases carotid artery, or invades mediastinal structures. (from AJCC 7th Ed.) 